\title{
Evaluation of the corrosion inhibition effect of the combined admixture of rosemary and cinnamon cassia oil on mild steel in weak acid electrolyte
}

\author{
Roland Tolulope Loto \\ Department of Mechanical Engineering, Covenant University, Ota, Ogun State, Nigeria
}

\section{A R T I C L E I N F O}

\section{Keywords:}

Corrosion

Essential oil

Inhibitor

Carbon steel

\begin{abstract}
A B S T R A C T
The corrosion resistance of mild steel (MS) in $0.5 \mathrm{M} \mathrm{H}_{2} \mathrm{SO}_{4}$ and $\mathrm{HCl}$ solution with specific concentrations of the intermixture of rosemary and cinanamon cassia essential oil extracts (RCC) was studied by potentiodynamic polarization method, open circuit potential analysis (OCP) and optical macroscopy. Information obtained showed RCC effectively inhibited MS corrosion from the lowest to the highest concentrations in both acids with lowest inhibition result of $95.30 \%$ and $94.19 \%$, and highest inhibition efficiency of $99.21 \%$ and $97.69 \%$. RCC exhibited dominant cathodic inhibition effect in $\mathrm{H}_{2} \mathrm{SO}_{4}$ due to suppression of the reduction reactions while in $\mathrm{HCl}$ RCC displayed mixed inhibition properties due to surface coverage effect in the presence of $\mathrm{Cl}^{-}$anions. OCP showed RCC increased the thermodynamic tendency of MS to corrosion in $\mathrm{H}_{2} \mathrm{SO}_{4}$ solution despite effective inhibition performance with significant electronegative shift in corrosion potential. In $\mathrm{HCl}$ significant electropositive potential displacement was observed relative to the potential of the control MS due to adsorbed protonated RCC molecules unto the steel. Adsorption of RCC molecules on MS aligned with Langmuir, Frumkin and Freundlich isotherm models through chemisorption mechanism in both acids with average correlation coefficient value above 0.9. Optical images of MS in both acids without RCC showed severe surface degradation with the degree of degradation being higher from $\mathrm{H}_{2} \mathrm{SO}_{4}$ solution. Optical images from RCC inhibited steel depict effective surface protection.
\end{abstract}

\section{Introduction}

Carbon steels is a metal alloy consisting majorly of Fe and C. Other elements in very small quantities are $\mathrm{Mn}, \mathrm{Si}$ and $\mathrm{Cu}$. The relatively low cost of carbon steels compared to stainless steels is the major factor for their universal application. Other important factors; such as availability, desirable mechanical properties, recyclability and ease of production (micro-alloying and heat treatment) significantly contributes to their marketability and applications. Their properties provide a good threshold for which other tool steels are compared (Novotny and Banerjee, 2016). The extensive applications of carbon steels ranges from oil and gas, to marine, construction, industrial plants, machineries and equipment's, desalination plants, automobile, fertilizer production and process industries (Zarras and Stenger-Smith, 2014). The useful lifespan of carbon steels is limited by their weak corrosion resistance in aqueous environments especially high humidity or saline-industrial conditions which creates operational problems for equipment and plants. Carbon steel piping and tubing are vulnerable to degradation from mechanical action by particle infested moving solution. In oxidizing environment, the steels are susceptible to pitting corrosion (Mutahhar et al., 2017; Ahn, 2013). Other factors responsible for carbon steel corrosion are aqueous $\mathrm{O}_{2}$, material factors, solution $\mathrm{pH}$, temperature, alkalis, $\mathrm{CO}_{2}$, presence of geothermal fluids, $\mathrm{H}_{2}$ effect (Ahmad, 2006). However, they are most often prone general corrosion which manifest in rust form and formation of surface oxides. Despite the huge advancement in corrosion prevention and control, the corrosion problem is prevalent in most industries which is estimated to be about US $\$ 2.2$ trillion annually worldwide (Saji, 2012). Prevention of carbon steel corrosion is often more practical and achievable than its total elimination. Corrosion prevention and control methods for carbon steels includes, appropriate system design, alloy modification, surface modification, materials selection, non-destructive testing and inspections, coatings, cathodic protection, anodic protection repairs, and other maintenance operations etc. (Schleider, 2009). Despite the numerous corrosion prevention/protection techniques, versatility, applicability and cost limit their application. Chemical compounds known as corrosion inhibitors combines' excellent performance with low cost and versatility in most industrial environments. These compounds significantly reduce the

E-mail address: tolu.loto@gmail.com. 
electrochemical deterioration of carbon steels through formation of a protective coating on the steels, alteration of the astringent media and distinctive deposition on the steel surface. Most of the conventional inhibitors such as phosphates, chromates, nitrites, nitrates etc. are of inorganic origin, toxic and costly. Organic inhibitor compounds are less toxic but unsustainable on the long term due to cost and environmental concerns (Geethamani et al., 2019; Lai et al., 2017; Soltani et al., 2010; Chugh et al., 2019, 2020; Singh et al., 2019). Previous investigations on the inhibition performance of biodegradable compounds have produced mixed but promising results (Li et al., 2005; Quartarone et al., 2012; Ashassi-Sorkhabi et al., 2004; ÖZcan, 2008; Olivares et al., 2006; Fu et al., 2010). Inhibition performance of extracts of essential oils have been studied in past with results showing their performance varies substantially with extract concentration (Bouoidina et al., 2017; El Ouariachi et al., 2015; Umoren et al., 2016; Salghi et al., 2015). Inhibition performance of Atlas cedar essential oil on carbon steel in $\mathrm{HCl}$ electrolyte was studied by Idouhli et al. (2017). Results obtained showed the essential oil performance exceeded $88 \%$ with respect to concentration and increases as concentration increases by chemical adsorption on the surface. El-Ouadi (El ouadi et al., 2014) evaluated Salvia oficinalis as corrosion inhibitor for carbon steel in $\mathrm{HCl}$. The oil extract exhibited mixed type inhibition performance with optimal inhibition result of $88.11 \%$. The extract performed poorly at low concentrations. Orange zest essential oil was researched into for its corrosion inhibition properties on mild steel in $1 \mathrm{M} \mathrm{HCl}$ medium. Maximum inhibition efficiency of $75.64 \%$ at $2.5 \mathrm{~g} \mathrm{~L}^{-1}$ concentration of the extract was observed. Inhibition occurred through chemisorption adsorption mechanism (Bensouda et al., 2019). Thymus satureioides oil was analyzed a green inhibitor for tinplate in dilute $\mathrm{HCl}$ solution. Results showed the oil displayed mixed type inhibition performance. The data revealed that the oil exhibit good inhibition even at moderate to high temperatures. The oil generally performed poorly at most concentrations. However at optimal concentration the inhibition performance exceeded $80 \%$ (Bammou et al., 2010). Lahhit et al. (2011) studied the corrosion inhibition effect of Foeniculum vulgare essential oil on carbon steel in $\mathrm{HCl}$ solution and observed the oil displayed mixed type inhibition performance with optimal inhibition efficiency of 76\%. The extracts show that inhibition performance strongly varies with oil extract concentration. This is disadvantageous in field applications. There is need for inhibitor compounds with generally constant inhibition result with respect to concentration. Further research is necessary to formulate biodegradable compounds with optimal inhibition effect at minimal concentrations. This research studies the synergistic combination effect of rosemary and cinnamon cassia essential oil extracts on mild steel in weak $\mathrm{H}_{2} \mathrm{SO}_{4}$ and $\mathrm{HCl}$ electrolyte. Results from previous investigation of the individual inhibition effect of both essentials oils are impressive but significantly concentration dependent (El Ouariachi et al., 2010; Dahmani et al., 2017).

\section{Experimental procedure}

\subsection{Material}

Mild steel (MS) rod whose elemental content is shown in Table 1 after analysis at the Physical Metallurgy Laboratory, Department of Mechanical Engineering, Covenant University, Ota, Ogun State, Nigeria was acquired in Lagos, Nigeria with diameter of $6 \mathrm{~mm}$. The steel was cut into 6 separate samples with mean length of $6 \mathrm{~mm}$. Rosemary and cinnamon cassia essential oil extracts (RCC) procured from NOW Foods, USA were admixed together in ratio $1: 3$ to study their combined corrosion inhibition properties on MS. The extracts have a combined molar mass of $1414.67 \mathrm{~g} / \mathrm{cm}^{3}$ (Prabodh et al., 2017; Cassia oil. https://pubch). RCC was prepared in percentage concentrations of $1 \%$, $1.5 \%, 2 \%, 2.5 \%$ and $3 \%$ per $200 \mathrm{ml}$ of $0.5 \mathrm{M}$ of standard grade $\mathrm{H}_{2} \mathrm{SO}_{4}$ (98\%) and $\mathrm{HCl}$ solution (37\%).

Potentiodynamic polarization was done with triple cord electrode wire (Pt counter electrode, $\mathrm{MS}$ electrode and $\mathrm{Ag} / \mathrm{AgCl}$ reference electrode) inside an acid solution, joined to electrochemical workstation (Digi-Ivy potentiostat). MS electrode was nested in pre-solidified resin paste with visible surface of $1.13 \mathrm{~cm}^{2}$. MS surface was grinded with abrasive sheets $(80,120,220,800$ and 1000 grits) and brightened with 6 $\mu \mathrm{m}$ diamond fluid. Digi-ivy potentiostat was joined to the computer for real-time corrosion monitoring from $-1.5 \mathrm{~V}$ to $+1.5 \mathrm{mV}$ at sweep rate of $0.0015 \mathrm{~V} \mathrm{~s}^{-1}$. Corrosion current density $\left(J_{\mathrm{CD}}\right)$ and corrosion potential $\left(E_{\mathrm{CP}}\right)$ were determined from the Tafel plots. Corrosion rate $\left(C_{\mathrm{R}}\right)$ was gotten from the mathematical relationship in equation (1);

$C_{R}=0.00327 \times J_{\mathrm{CD}} \times Q_{\mathrm{wT} / D}$

$D\left(\mathrm{~g} / \mathrm{cm}^{3}\right)$ represents density and $Q_{W T}(\mathrm{~g})$ represents equivalent. Inhibition efficiency $(\eta)$ was obtained from equation (2);

$\eta=1-\left[\frac{C_{2}}{C_{1}}\right] \times 100$

$C_{1}$ and $C_{2}$ indicates corrosion rate of MS with and without RCC inhibitor compound. Open circuit potential study of MS within the acid-inhibitor solution was done at step potential of $0.1 \mathrm{~V} \mathrm{~s}^{-1}$ for $3600 \mathrm{~s}$ with Digi-ivy potentiostatic device. Optical macroscopic studies of MS surface prior to corrosion test and subsequently after corrosion was studied through Omax trinocular metallurgical microscope.

\section{Results and discussion}

\subsection{Potentiodynamic polarization studies}

Potentiodynamic polarization plots of MS corrosion and inhibition in $\mathrm{H}_{2} \mathrm{SO}_{4}$ and $\mathrm{HCl}$ solution at specific RCC concentration are displayed in Fig. 1(a) and (b). Results from the polarization experiment are displayed in Table 2. Inspection of Table 2 shows substantial difference between MS corrosion rate in $\mathrm{H}_{2} \mathrm{SO}_{4}$ and $\mathrm{HCl}$ solution at $0 \%$ RCC concentration compared to the acid solution at higher RCC concentrations. This results from significant oxidation of MS surface in the acid media leading to accelerated discharge of $\mathrm{Fe}^{2+}$ ions into the acid solution. This mechanism degrades the steel resulting in loss of mechanical, physical and aesthetic properties of the steel. Inspection of the plots exhibited in Fig. 1(a) and (b) at 0\% RCC concentration shows the slopes of the anodic-cathodic polarization are significantly higher than the slopes of the polarization plots at specific RCC concentrations. MS corrosion rate ( $0 \%$ RCC concentration) in $\mathrm{H}_{2} \mathrm{SO}_{4}$ at $13.52 \mathrm{~mm} / \mathrm{y}$ is visibly greater than the figure obtained in $\mathrm{HCl}$ solution at $4.12 \mathrm{~mm} / \mathrm{y}$ due to the greater dissociation of $\mathrm{H}_{2} \mathrm{SO}_{4}$ in $\mathrm{H}_{2} \mathrm{O}$ compared to $\mathrm{HCl}$. At $0 \%$ RCC concentration, the corresponding corrosion current density and polarization resistance in both acids are $1.18 \times 10^{-3} \mathrm{~A} / \mathrm{cm}^{2}$ and $3.61 \times 10-4 \mathrm{~A} / \mathrm{cm}^{2}$, and $19.19 \Omega$ and $62.91 \Omega$. In $\mathrm{H}_{2} \mathrm{SO}_{4}$ solution, RCC at $1 \%$ concentration significantly reduced the corrosion rate to $0.64 \mathrm{~mm} / \mathrm{y}$ relating to inhibition result of $95.30 \%$ and polarization resistance of $408.40 \Omega$. Further increase in corrosion rate results in minimal but progressive reduction in corrosion rate and increment in inhibition efficiency with peaked at $3 \%$ RCC concentration with corrosion rate of $0.11 \mathrm{~mm} / \mathrm{y}$ and inhibition result of $99.21 \mathrm{~mm} / \mathrm{y}$. The polarization plots of MS at $1 \%-3 \%$ RCC

Table 1

Elemental composition (wt. \%) of MS.

\begin{tabular}{|c|c|c|c|c|c|c|c|c|c|}
\hline Element & $\mathrm{C}$ & $\mathrm{Si}$ & Mn & $\mathrm{P}$ & S & $\mathrm{Cu}$ & $\mathrm{Ni}$ & $\mathrm{Al}$ & $\mathrm{Fe}$ \\
\hline Composition & $0.40 \%$ & $0.17 \%$ & $0.44 \%$ & $0.01 \%$ & $0.01 \%$ & $0.08 \%$ & $0.01 \%$ & $0.03 \%$ & Balance \\
\hline
\end{tabular}




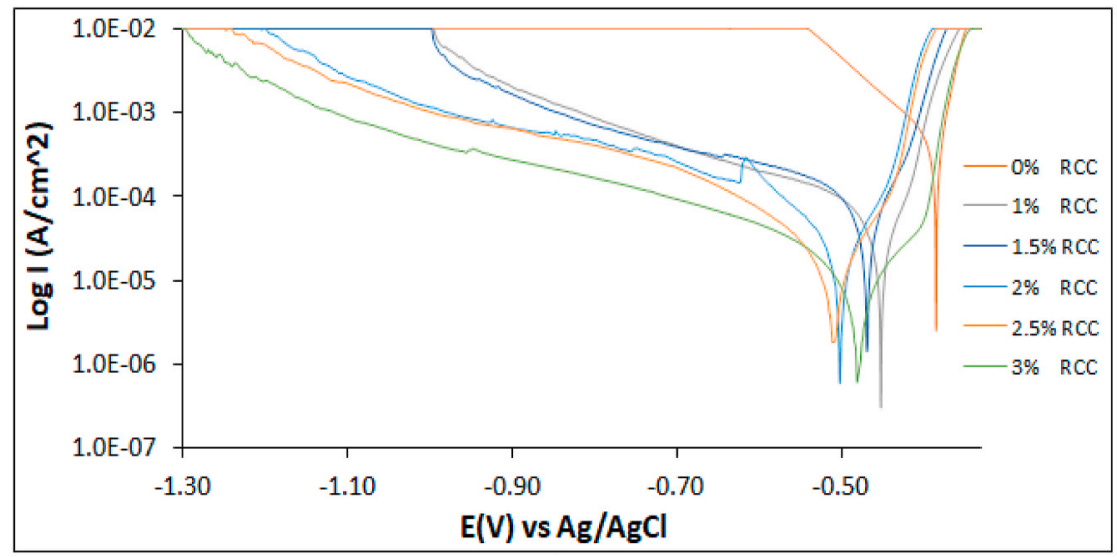

(a)

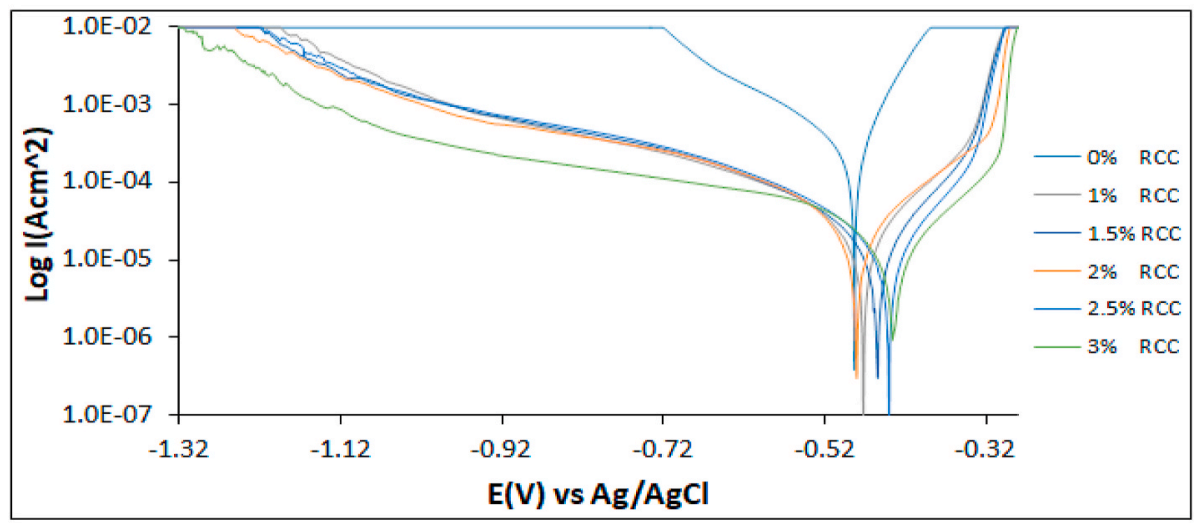

(b)

Fig. 1. Plots obtained from the potentiodynamic polarization of Ms at specific RCC concentration in (a) $\mathrm{H}_{2} \mathrm{SO}_{4}$ solution and (b) $\mathrm{HCl}$ solution.

Table 2

Results from potentiodynamic polarization of $\mathrm{MS}$ in $\mathrm{H}_{2} \mathrm{SO}_{4}$ and $\mathrm{HCl}$ solution at specific RCC concentration.

\begin{tabular}{|c|c|c|c|c|c|c|c|c|c|}
\hline \multicolumn{10}{|l|}{$\mathrm{H}_{2} \mathrm{SO}_{4}$} \\
\hline Sample & RCC Conc. (\%) & $\mathrm{LCS} C_{\mathrm{R}}(\mathrm{mm} / \mathrm{y})$ & RCC $\xi_{\mathrm{F}}(\%)$ & $C_{\mathrm{I}}(\mathrm{A})$ & $C_{J}\left(\mathrm{~A} / \mathrm{cm}^{2}\right)$ & $C_{\mathrm{P}}(\mathrm{V})$ & $R_{\mathrm{p}}(\Omega)$ & $B_{\mathrm{c}}(\mathrm{V} / \mathrm{dec})$ & $B_{\mathrm{a}}(\mathrm{V} / \mathrm{dec})$ \\
\hline A & 0 & 13.52 & 0 & $1.34 \mathrm{E}-03$ & $1.18 \mathrm{E}-03$ & -0.385 & 19.19 & -8.560 & 8.233 \\
\hline B & 1 & 0.64 & 95.30 & $6.29 \mathrm{E}-05$ & 5.57E-05 & -0.452 & 408.40 & -4.057 & 25.320 \\
\hline $\mathrm{C}$ & 1.5 & 0.51 & 96.20 & $5.09 \mathrm{E}-05$ & 4.50E-05 & -0.469 & 582.70 & -3.569 & 33.710 \\
\hline $\mathrm{D}$ & 2 & 0.35 & 97.42 & $3.45 \mathrm{E}-05$ & $3.05 \mathrm{E}-05$ & -0.502 & 745.30 & -9.018 & 41.670 \\
\hline E & 2.5 & 0.20 & 98.51 & $2.00 \mathrm{E}-05$ & $1.77 \mathrm{E}-05$ & -0.509 & 1284.00 & -6.705 & 32.790 \\
\hline $\mathrm{F}$ & 3 & 0.11 & 99.21 & $1.06 \mathrm{E}-05$ & $9.41 \mathrm{E}-06$ & -0.479 & 2417.00 & -5.778 & 22.070 \\
\hline $\begin{array}{l}\mathrm{HCl} \\
\text { Sample }\end{array}$ & RCC Conc. (\%) & $\mathrm{LCS} C_{\mathrm{R}}(\mathrm{mm} / \mathrm{y})$ & RCC $\xi_{\mathrm{F}}(\%)$ & $C_{\mathrm{I}}(\mathrm{A})$ & $C_{J}\left(\mathrm{~A} / \mathrm{cm}^{2}\right)$ & $C_{\mathrm{P}}(\mathrm{V})$ & $R_{\mathrm{p}}(\Omega)$ & $B_{\mathrm{c}}(\mathrm{V} / \mathrm{dec})$ & $B_{\mathrm{a}}(\mathrm{V} / \mathrm{dec})$ \\
\hline A & 0 & 4.12 & 0 & 4.08E-04 & 3.61E-04 & -0.483 & 62.91 & -6.792 & 15.340 \\
\hline B & 1 & 0.24 & 94.19 & 2.37E-05 & $2.10 \mathrm{E}-05$ & -0.472 & 1184.00 & -5.839 & 9.192 \\
\hline C & 1.5 & 0.21 & 94.95 & $2.06 \mathrm{E}-05$ & $1.82 \mathrm{E}-05$ & -0.454 & 1247.00 & -6.655 & 9.060 \\
\hline $\mathrm{D}$ & 2 & 0.20 & 95.09 & $2.00 \mathrm{E}-05$ & 1.77E-05 & -0.480 & 1416.00 & -5.946 & 8.059 \\
\hline E & 2.5 & 0.15 & 96.25 & $1.53 \mathrm{E}-05$ & $1.35 \mathrm{E}-05$ & -0.440 & 1680.00 & -6.606 & 8.120 \\
\hline $\mathrm{F}$ & 3 & 0.10 & 97.69 & $9.41 \mathrm{E}-06$ & $1.16 \mathrm{E}-05$ & -0.434 & 1902.00 & -5.813 & 9.375 \\
\hline
\end{tabular}

concentration in Fig. 1(a) shows significant cathodic shift with respect to the plot at $0 \%$ RCC concentration. The cathodic shift varies with respect to RCC concentration with maximum potential shift of $124 \mathrm{mV}$ signifying cathodic inhibition mechanism on $\mathrm{MS}$ in $\mathrm{H}_{2} \mathrm{SO}_{4}$ solution. The extensive cathodic polarization plot which significantly decreased with increase in RCC concentration proves this assertion. The observation shows RCC compound inhibits MS corrosion by suppressing the $\mathrm{H}_{2}$ evolution and $\mathrm{O}_{2}$ reduction reactions through selective precipitation onto MS, increase in its surface impedance and modification of the corrosive medium through formation of complex precipitates with the corrosive species.

RCC compound significantly decreased MS corrosion rate in $\mathrm{HCl}$ solution. Observation of Table 2 shows that generally the corrosion rate obtained at specific RCC concentration in $\mathrm{HCl}$ solution are slightly lower than the values obtained in $\mathrm{H}_{2} \mathrm{SO}_{4}$ concentration. At $1 \%$ RCC concentration, MS corrosion rate is $0.24 \mathrm{~mm} / \mathrm{y}$ while at $3 \%$ RCC concentration, corrosion rate value of $0.10 \mathrm{~mm} / \mathrm{y}$ was obtained. However, the related inhibition efficiency values obtained are between $94.19 \%$ and $97.69 \%$ which are below the results obtained in $\mathrm{H}_{2} \mathrm{SO}_{4}$ solution for reasons earlier explained and the fact that MS corrosion rate $0 \%$ is $4.12 \mathrm{~mm} / \mathrm{y}$ 
compared to $13.52 \mathrm{~mm} / \mathrm{y}$ in $\mathrm{H}_{2} \mathrm{SO}_{4}$ solution. The polarization resistance values obtained in $\mathrm{HCl}$ solution confirms the lower corrosion rate results which are roughly greater than the results obtained in $\mathrm{H}_{2} \mathrm{SO}_{4}$ solution. The slopes of the anodic-cathodic in Fig. 1(b) at specific RCC concentration show significant anodic and cathodic inhibition effect. The near similarity of the slopes shows RCC inhibition performance is under activation control. The maximum corrosion potential variation of the slopes with respect to the potential of the slope at $0 \%$ RCC concentration shows a maximum corrosion potential difference of $49 \mathrm{mV}$ indicating mixed type inhibition performance. This proves inhibition approach of RCC compound is through the mechanism earlier mentioned for RCC in $\mathrm{H}_{2} \mathrm{SO}_{4}$ solution and secondly by surface coverage whereby RCC adsorb onto the steel through electrostatic attraction and covalent bonding whereby the redox reaction processes are suppressed and corrosive anions in the acid solution are inhibited from getting to the steel surface. Contrary to the observation from previous research on essential oils (Idouhli et al., 2017; El ouadi et al., 2014; Bensouda et al., 2019; Bammou et al., 2010; Lahhit et al., 2011), RCC performed effectively at all concentrations studied. Its performance is not subject to its concentration. Hence it is reliable in field applications where determinant factors are variable.

\subsection{Open circuit potential analysis}

Open circuit potential (OCP) curves of MS corrosion potential against time of exposure in $\mathrm{H}_{2} \mathrm{SO}_{4}$ and $\mathrm{HCl}$ media at $0 \%, 1 \%$ and $3 \%$ RCC concentration are displayed in Fig. 2(a) and (b). The OCP curves in Fig. 2 (a) at $0 \%$ RCC concentration shifted to electropositive potentials compared to the curves at $1 \%$ and $3 \%$ RCC concentration. The curve originated at $-0.464 \mathrm{~V}(0 \mathrm{~s})$ and increased sequentially to $-0.407 \mathrm{~V}$ at $3600 \mathrm{~s}$ due to growth of pseudo protective oxide. The potential transients are due to instability of the porous oxide on the steel surface. The OCP curves at $1 \%$ and $3 \%$ RCC concentration initiated at potentials of $-0.416 \mathrm{~V}$ and $-0.419 \mathrm{~V}(0 \mathrm{~s})$, and sequentially underwent cathodic displacement. The curve at 3\% RCC shifted sharply before attaining relative thermodynamic stability from $400 \mathrm{~s}(-0.444 \mathrm{~V})$ to $3208.53 \mathrm{~s}$ at $-0.466 \mathrm{~V}$. Beyond this potential, a sharp shift in potential was observed to electropositive values. It must be noted that the general electronegative values observed at $1 \%$ and $3 \%$ RCC concentration shows RCC despite it effective inhibition performance from potentiodynamic polarization, increases the thermodynamic tendency of MS to corrode i.e. the protective film by RCC compound is unstable. The curves in Fig. 2(b) differ from the plot in Fig. 2(a), at 0\% RCC concentration the OCP curve is most electronegative. The plot originated at $-0.485 \mathrm{~V}(0 \mathrm{~s})$ and sequentially displaced to electropositive potentials. Relative thermodynamic stability was attained at $1131.81 \mathrm{~s}(-0.455 \mathrm{~V})$ till $3600 \mathrm{~s}(-0.444$ V). The OCP curves at $1 \%$ and $3 \%$ RCC concentration were relatively electropositive compared to the plot at $0 \%$ RCC. However, they slightly shifted to electronegative values. These curves originated at $-0.389 \mathrm{~V}$ and $-0.383 \mathrm{~V}(0 \mathrm{~s})$ and culminated at $-0.470 \mathrm{~V}$ and $-0.430 \mathrm{~V}(3600 \mathrm{~s})$. Their plot configuration and relative electropositive values shows RCC compound reduced the thermodynamic propensity of MS to corrode in $\mathrm{HCl}$ solution in comparison to the observation in $\mathrm{H}_{2} \mathrm{SO}_{4}$ solution. This shows RCC protective film in $\mathrm{HCl}$ solution is more stable in addition to the effective inhibition performance from potentiodynamic polarization test.

\subsection{Corrosion thermodynamics}

Corrosion inhibition of the redox electrochemical process by RCC on MS surface in $\mathrm{H}_{2} \mathrm{SO}_{4}$ and $\mathrm{HCl}$ solution was studied through mathematical models and plots depicting the deviation of the aggregate RCC ionized molecular species attracted to and adsorbed on the steel surface at stable temperature (Bockris and Swinkels, 1964). Results from potentiodynamic polarization shows RCC performed effectively in $\mathrm{H}_{2} \mathrm{SO}_{4}$ and $\mathrm{HCl}$ solution. Open circuit potential studies show the corrosion inhibition of RCC on MS in $\mathrm{H}_{2} \mathrm{SO}_{4}$ solution is thermodynamically unstable. RCC in the acid media protonates and attached themselves to the steel especially the reactive sites stifling the corrosion reaction process responsible to surface degradation. However, forces responsible for this are either strong covalent forces or weak van der waals forces which occur through adsorption whereby aggregation of RCC molecules from the aqueous phase occurs on the charged metal surface. Potentiodynamic polarization data were evaluated with four adsorption isotherms. The most applicable isotherms were identified from their correlation coefficient values. The correlation coefficients of Langmuir, Frumkin and Frundlich adsorption isotherms are displayed in Table 3 below.

The Langmuir plots from $\mathrm{H}_{2} \mathrm{SO}_{4}$ and $\mathrm{HCl}$ solutions are depicted Fig. 3 (a) and (b). Langmuir isotherm states that the adsorbate protonated inhibitor molecule are strongly attracted to specific number of sites on the adsorbent steel surface through molecular attraction wherewith the chemical activity of the inhibitor molecules is proportional to the fraction of occupied steel surface sites on the assumption that the surface is non-heterogeneous without any lateral interaction effect between the

Table 3

Correlation coefficient data of applicable adsorption isotherms from $\mathrm{H}_{2} \mathrm{SO}_{4}$ and $\mathrm{HCl}$ solution.

\begin{tabular}{lll}
\hline Isotherms Model & $\mathrm{H}_{2} \mathrm{SO}_{4}$ & $\mathrm{HCl}$ \\
\hline Langmuir & 0.9999 & 0.9996 \\
Frumkin & 0.7755 & 0.9704 \\
Frundlich & 0.9777 & 0.8381 \\
\hline
\end{tabular}

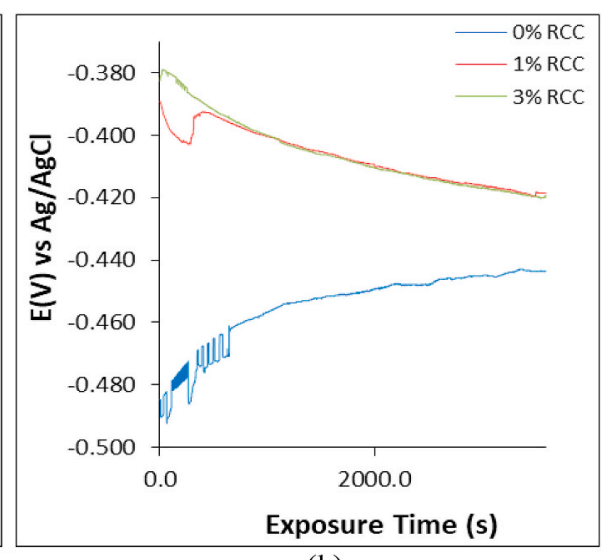

(b)

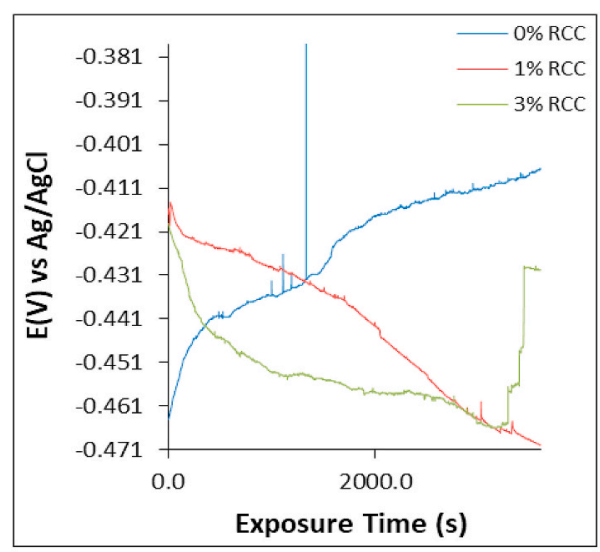

(a)
Fig. 2. OCP plots of MS at $0 \%, 1 \%$ and $3 \%$ RCC concentration in (a) $\mathrm{H}_{2} \mathrm{SO}_{4}$ solution and (b) $\mathrm{HCl}$ solution. 


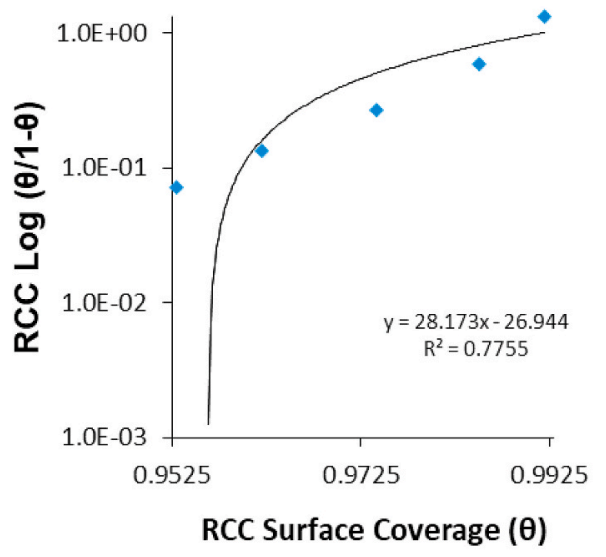

(a)

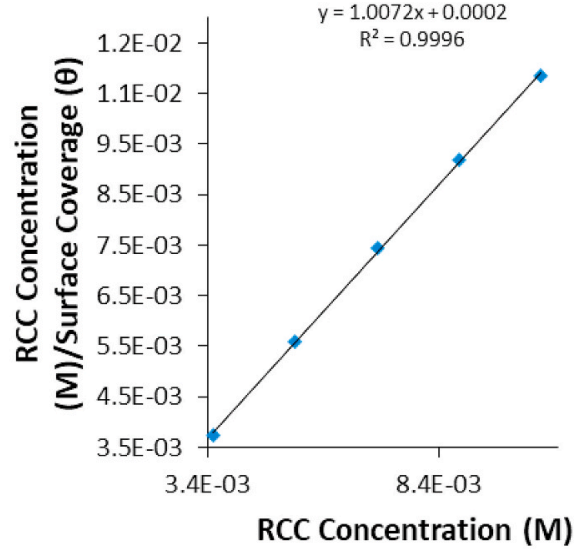

(b)

Fig. 3. Langmuir adsorption isotherm plot from (a) $\mathrm{H}_{2} \mathrm{SO}_{4}$ solution and (b) $\mathrm{HCl}$ solution.

inhibitor molecules adsorbed with respect to the following mathematical expression;

$\theta=\left[\frac{K_{\mathrm{ads}} C_{\mathrm{RCC}}}{1+K_{\mathrm{ads}} C_{\mathrm{RCC}}}\right]$

$K_{\text {ads }}$ represents the equilibrium constant of adsorption. $C_{\mathrm{RCC}}$ represents the molar concentration of $\mathrm{H}_{2} \mathrm{O}$. Frumkin isotherm assumes the molecular coverage on heterogeneous metallic surfaces is the same at high molecular concentrations with respect to the potential of the surface. Lateral interaction effect among the inhibitor molecules is significant and quantitative with respect to the following equation;

$\log \left[C_{\mathrm{RCC}} *(\theta / 1-\theta)\right]=2.303 \log K_{\mathrm{ads}}+2 \alpha \theta$

$\alpha$ is the lateral interaction parameter. The Frumkin isotherm plots from $\mathrm{H}_{2} \mathrm{SO}_{4}$ and $\mathrm{HCl}$ solution are shown in Fig. 4(a) and (b). Freundlich isotherm exhibits a mathematical model for the adsorption equilibrium between adsorbate inhibitor molecule and adsorbent steel surface, and the lateral interaction effect between them. The Freundlich equation expresses the isothermal differentiation of adsorption of a fluid onto an adsorbent surface. Freundlich isotherm focuses on adsorbed molecular interaction on adsorbent surfaces and the lateral interaction effect amidst the RCC molecules (Zeldowitsch, 1934; Aharoni and Ungarish, 1977). Freundlich equation is expressed as shown below;

$\theta=K C^{\mathrm{n}}$

$\log \theta=\operatorname{nlog} C+\log K_{\text {ads }}$ $\mathrm{n}$ represents the constant for the properties of adsorbed RCC molecule. The Freundlich isotherm plots from $\mathrm{H}_{2} \mathrm{SO}_{4}$ and $\mathrm{HCl}$ solution are depicted in Fig. 5(a) and (b).

Data for the adsorption energy [Gibbs free energy $(\Delta G)$ ] for RCC onto MS surface in $\mathrm{H}_{2} \mathrm{SO}_{4}$ and $\mathrm{HCl}$ solution are presented in Table 4. The data was calculated from the equation below. The equilibrium constant of adsorption $\left(K_{\mathrm{ads}}\right)$ in $\mathrm{H}_{2} \mathrm{SO}_{4}$ and $\mathrm{HCl}$ solution was calculated from Langmuir isotherm equation due to their high correlation coefficient value.

$\Delta G_{\text {ads }}=-2.303 R T \log \left[55.5 K_{\text {ads }}\right]$

55.5 represents molar concentration of $\mathrm{H}_{2} \mathrm{O}$ in the acid/inhibitor solution, $R$ represents universal gas constant and $T$ represents absolute temperature. The $\Delta G$ values from both acids shows the adsorption mode by RCC is through chemisorption mechanism whereby protonated RCC molecules are strongly drawn to the steel surface through covalent interactions (Loto et al., 2016; Loto, 2016; Loto et al., 2014). $\Delta G$ values show $\mathrm{H}_{2} \mathrm{O}$ molecules was effectively substituted from the aqueous electrolyte by RCC molecules. The $\Delta G$ values in both solutions ranges from (lowest - highest) $-47.32 \mathrm{~kJ} \mathrm{~mol}^{-1}$ to $-50.30 \mathrm{~kJ} \mathrm{~mol}^{-1}$ signifying strong energy attractions. The higher value of $\Delta G$ in $\mathrm{H}_{2} \mathrm{SO}_{4}$ solution is due to the strong ionization potential of $\mathrm{H}_{2} \mathrm{SO}_{4}$ in $\mathrm{H}_{2} \mathrm{O}$ compared to $\mathrm{HCl}$. The $\Delta G$ values also show the lateral interaction reaction between ionized molecules in negligible.

\subsection{Optical image analysis}

Optical images of MS (mag. $\times 20$ ) prior to corrosion and subsequently

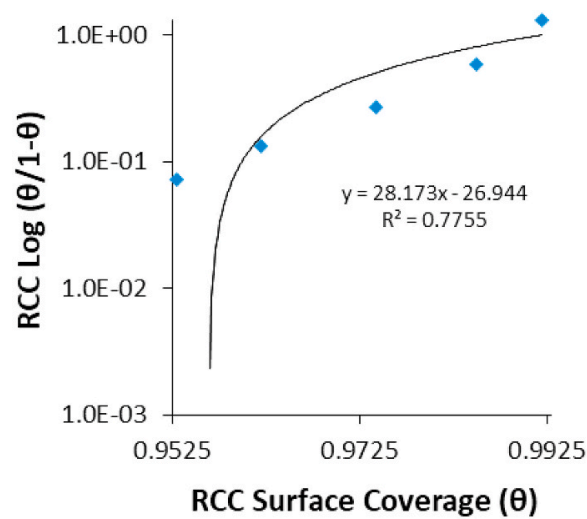

(a)

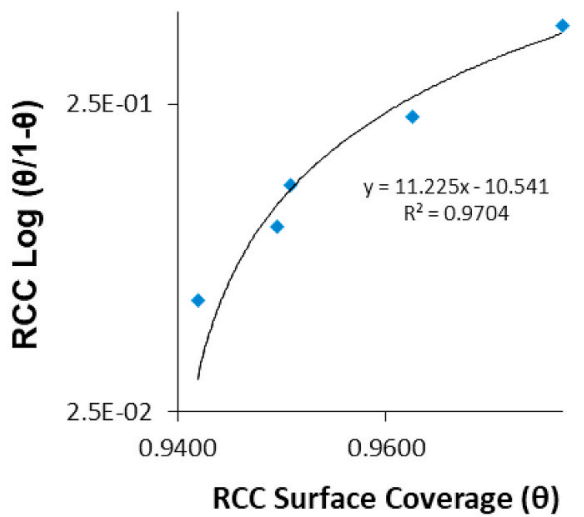

(b)

Fig. 4. Frumkin adsorption isotherm plots from (a) $\mathrm{H}_{2} \mathrm{SO}_{4}$ solution and (b) $\mathrm{HCl}$ solution. 


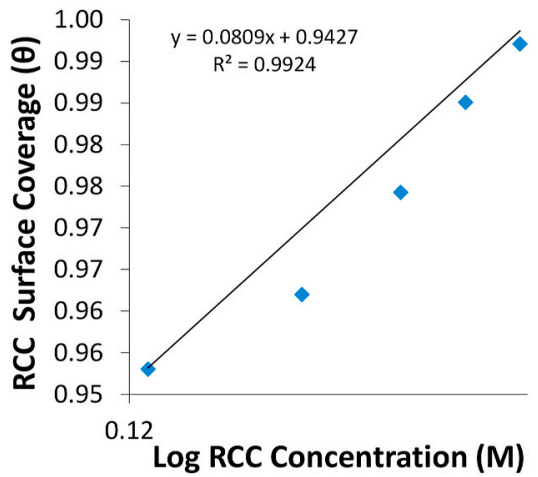

(a)

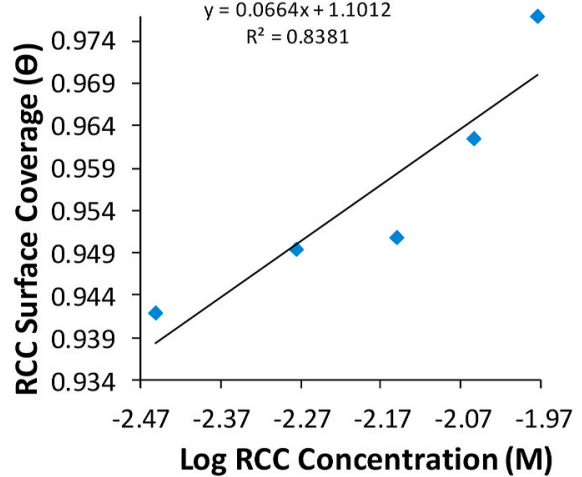

(b)

Fig. 5. Freundlich adsorption isotherm plots from (a) $\mathrm{H}_{2} \mathrm{SO}_{4}$ solution and (b) $\mathrm{HCl}$ solution.

Table 4

Thermodynamic data of the inhibition mechanism on MS in $\mathrm{H}_{2} \mathrm{SO}_{4}$ and $\mathrm{HCl}$ solution.

\begin{tabular}{|c|c|c|c|c|}
\hline MS Samples & RCC Concentration (M) & Surface Coverage $(\theta)$ & Equilibrium Constant of adsorption $(K)$ & Gibbs Free Energy, $\Delta G\left(\mathrm{Kjmol}^{-1}\right)$ \\
\hline A & 0 & 0 & 0 & 0 \\
\hline B & 0.003534 & 0.952999 & 5736815 & -48.52 \\
\hline $\mathrm{C}$ & 0.005302 & 0.961978 & 4772250 & -48.06 \\
\hline $\mathrm{D}$ & 0.007069 & 0.974244 & 5351030 & -48.34 \\
\hline $\mathrm{E}$ & 0.008836 & 0.985053 & 7458293 & -49.17 \\
\hline $\mathrm{F}$ & 0.010603 & 0.992059 & 11782848 & -50.30 \\
\hline MS Samples & RCC Concentration (M) & Surface Coverage $(\theta)$ & Equilibrium Constant of adsorption $(K)$ & Gibbs Free Energy, $\Delta G\left(\mathrm{Kjmol}^{-1}\right)$ \\
\hline A & 0 & 0 & 0 & 0 \\
\hline B & 0.003534 & 0.941904 & 4587182 & -47.96 \\
\hline $\mathrm{C}$ & 0.005302 & 0.949503 & 3546709 & -47.32 \\
\hline $\mathrm{D}$ & 0.007069 & 0.9509 & 2739755 & -46.69 \\
\hline $\mathrm{E}$ & 0.008836 & 0.96252 & 2906362 & -46.83 \\
\hline $\mathrm{F}$ & 0.010603 & 0.976933 & 3994309 & -47.62 \\
\hline
\end{tabular}

after corrosion from $\mathrm{H}_{2} \mathrm{SO}_{4}$ and $\mathrm{HCl}$ solution without RCC, and after corrosion from both acids in the presence of RCC are shown from Figs. 6-8(b). Fig. 3 shows the optical image of MS before corrosion. The lines and serrated edges is due to cutting/machining of the steel surface. Fig. 7(a) and (b) exhibits the optical image of MS after corrosion from $\mathrm{H}_{2} \mathrm{SO}_{4}$ and $\mathrm{HCl}$ solution. Both images show severe surface degradation oxidation effect of $\mathrm{SO}_{4}^{2-}$ and $\mathrm{Cl}^{-}$anions within the acid media resulting

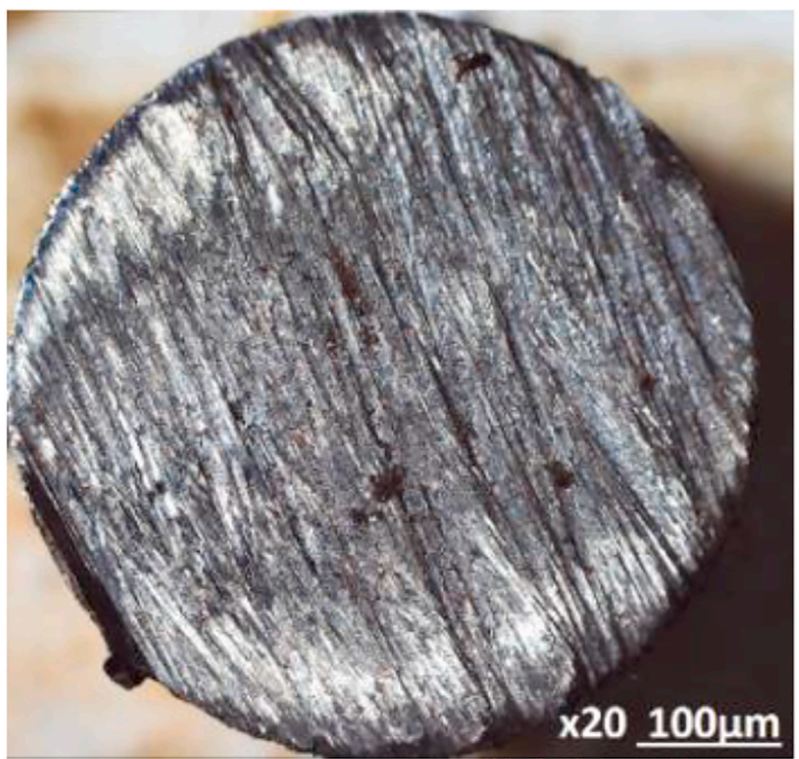

Fig. 6. Morphology of MS prior to corrosion test. in oxidation. The degree of degradation is much higher in Fig. 7(a) due the aggressive nature of $\mathrm{SO}_{4}^{2-}$ anion compare to $\mathrm{Cl}^{-}$. This was confirmed from the polarization test where the corrosion rate of MS at 0\% RCC concentration from $\mathrm{H}_{2} \mathrm{SO}_{4}$ solution was substantially greater than the results gotten from $\mathrm{HCl}$. While the degree of degradation shown in Fig. 7 (b) is significant, the deterioration tends to be localized due to the electrochemical action of $\mathrm{Cl}^{-}$ions. Addition of RCC compound significantly improved the optical images of MS in both acids as depicted in Fig. 8(a) and (b). The images show the surface coated with RCC oil after drying. The protective covering by RCC inhibition hindered the electrochemical action of the corrosive species, which in effect suppressed the reduction-oxidation reaction mechanism on the steel.

\section{Conclusion}

Admixture of rosemary and cinnamon cassia essential oil extracts substantially suppressed the degradation of mild steel in weak $\mathrm{H}_{2} \mathrm{SO}_{4}$ and $\mathrm{HCl}$ electrolytes with optimal inhibition result above $90 \%$ at all concentrations. The combined oil extracts displayed mixed type inhibition performance in $\mathrm{HCl}$ and cathodic inhibition in $\mathrm{H}_{2} \mathrm{SO}_{4}$ solution. The extracts inhibited the steel by adsorption through chemisorption mechanism from calculated Gibbs free energy values and correlation with convention isotherm models. $\mathrm{In}_{2} \mathrm{SO}_{4}$, the extracts increased the thermodynamic instability and tendency of the steel to corrode compared to its performance in $\mathrm{HCl}$ solution here the extracts passivate the steel and significantly decreases its tendency to corrode. Surface representations of mild steel subsequently after corrosion test in acid media without the extracts severely degraded compared to the morphology of the steel from the acid-extract solution. 


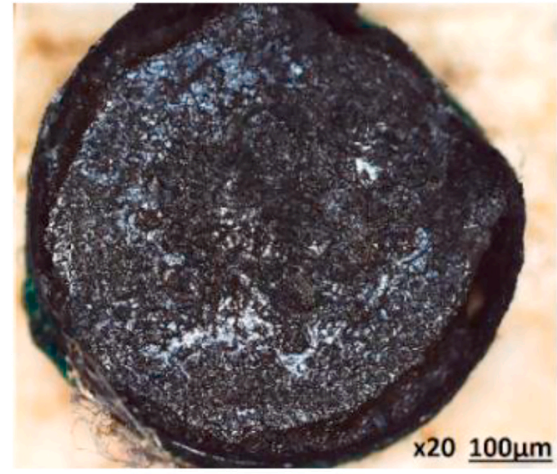

(a)

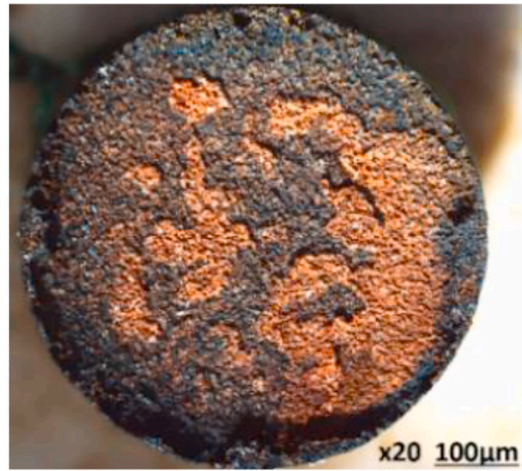

(b)

Fig. 7. Morphology of MS after corrosion without RCC compound from (a) $\mathrm{H}_{2} \mathrm{SO}_{4}$ solution and (b) $\mathrm{HCl}$ solution.

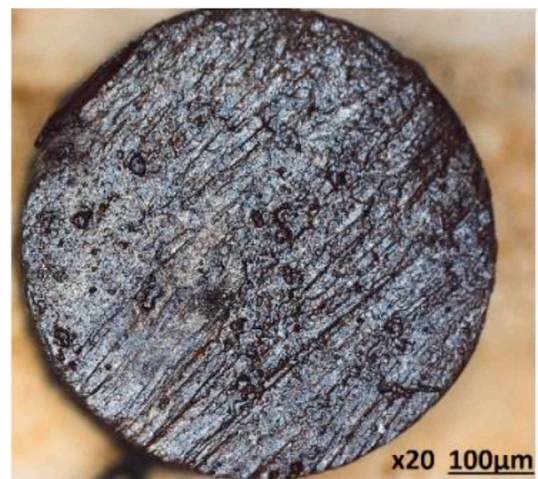

(a)

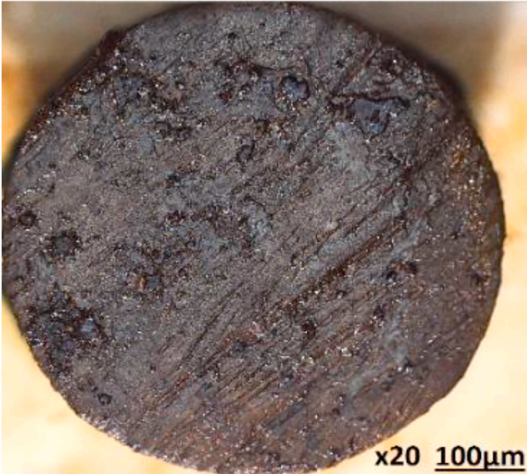

(b)

Fig. 8. Morphology of MS after corrosion in RCC/acid solution (a) in $\mathrm{H}_{2} \mathrm{SO}_{4}$ solution and (b) in $\mathrm{HCl}$ solution.

\section{Author statement}

The author is responsible for the experimental work, analysis of results, discussion of results and everything concerning the research.

\section{Declaration of competing interest}

The authors declare that they have no known competing financial interests or personal relationships that could have appeared to influence the work reported in this paper.

\section{Acknowledgement}

The author sincerely appreciates Covenant University for their support and provision of research facilities.

\section{Appendix A. Supplementary data}

Supplementary data to this article can be found online at https://doi. org/10.1016/j.scp.2020.100298.

\section{References}

Aharoni, C., Ungarish, M., 1977. Kinetics of activated chemisorption. Part 2. Theoretical models. J. Chem. Soc. Faraday. Trans. 73, 456-464.

Ahmad, Z., 2006. Chapter 9 - Selection of Materials for Corrosive Environment, Principles of Corrosion Engineering and Corrosion Control, pp. 479-549. https:// doi.org/10.1016/B978-075065924-6/50010-6.

Ahn, T.M., 2013. Chapter 7 - Assessing and Modelling the Performance of Nuclear Waste and Associated Packages for Long-Term Management, Radioactive Waste Management and Contaminated Site Clean-Up, Processes, Technologies and
International Experience. Woodhead Publishing Series in Energy, pp. 273-300, 301 .

Ashassi-Sorkhabi, H., Majidi, M.R., Seyyedi, K., 2004. Investigation of inhibition effect of some amino acids against steel corrosion in $\mathrm{HCl}$ solution. Appl. Surf. Sci. 225, $176-185$.

Bammou, L., Chebli, B., Salghi, R., Bazzi, L., Hammouti, B., Mihit, M., Idrissi, H., 2010. Thermodynamic properties of Thymus satureioides essential oils as corrosion inhibitor of tinplate in $0.5 \mathrm{M} \mathrm{HCl}$ : chemical characterization and electrochemical study. Green Chem. Lett. Rev. 3 (3), 173-178. https://doi.org/10.1080/ 17518251003660121.

Bensouda, Z., El Assiri, E., Sfaira, M., Touhami, M.E., Farah, A., Hammouti, B., 2019. Extraction, Characterization and Anticorrosion Potential of an essential oil from orange zest as eco-friendly inhibitor for mild steel in acidic solution. J. Bio. Tribo Corros. 5, 84. https://doi.org/10.1007/s40735-019-0276-y.

Bockris, J.O., Swinkels, D.A.J., 1964. Adsorption of n-decylamine on solid metal electrodes. J. Electrochem. Soc. 11, 736. https://doi.org/10.1149/1.2426222.

Bouoidina, A., Chaouch, M., Abdellaoui, A., Lahkimi, A., Hammouti, B., El-Hajjaji, F., Taleb, M., Nahle, A., 2017. Essential oil of "Foeniculum vulgare": antioxidant and corrosion inhibitor on mild steel immersed in hydrochloric medium, Anti-Corros. Methods Microbiol. 64 (5), 563-572.

Cassia Oil. https://pubchem.ncbi.nlm.nih.gov/compound/Cassia-oil.

Chugh, B., Singh, A.K., Thakur, S., Pani, B., Pandey, A.K., Lgaz, H., Chung, I.-M., Ebenso, E.E., 2019. An exploration about the interaction of mild steel with hydrochloric acid in the presence of N-(Benzo[d]thiazole-2-yl)-1-phenylethan-1 imines. J. Phys. Chem. C 123 (37), 22897-22917.

Chugh, B., Singh, K.A., Chaouiki, A., Salghi, R., Thakur, S., Pani, B., 2020. A comprehensive study about anti-corrosion behaviour of pyrazine carbohydrazide: gravimetric, electrochemical, surface and theoretical study. J. Mol. Liq. 299, 112160 .

Dahmani, K., Galai, M., Cherkaoui, M., El Hasnaoui, A., El Hessni, A., 2017. Cinnamon essential oil as a novel eco-friendly corrosion inhibitor of copper in $0.5 \mathrm{M}$ Sulfuric Acid medium. J. Mats. \& Environ. Sci. 8 (5), 1676-1689.

El ouadi, Y., Bouyanzer, A., Majidi, L., Paolini, J., Desjobert, J.M., Costa, J., Chetouani, A., Hammouti, B., 2014. Salvia officinalis essential oil and the extract as green corrosioninhibitor of mild steel in hydrochloric acid. J. Chem. Pharmaceut. Res. 6 (7), 1401-1416.

El Ouariachi, E., Paolini, J., Bouklah, M., Elidrissi, A., Bouyanzer, A., Hammouti, B., Desjobert, J.-M., Costa, J., 2010. Adsorption properties of Rosmarinus officinalis oil 
as green corrosion inhibitors on C38 steel in $0.5 \mathrm{M} \mathrm{H}_{2} \mathrm{SO}_{4}$. Acta Metall. Sin. 23 (1) 13-20. https://doi.org/10.11890/1006-7191-101-13.

El Ouariachi, H.E., Mokhtari, O., Salhi, A., Chahboun, N., ElMahi, B., Bouyanzer, A., Zarrouk, A., Hammouti, B., Costa, J., 2015. Chemical constituents and corrosion inhibition of mild steel by the essential oil of Thymus algeriensis in $1.0 \mathrm{M}$ hydrochloric acid solution. Der Pharma Chem. 7 (8), 252-264.

Fu, J., Li, S., Cao, L., Wang, Y., Yan, L., Lu, L., 2010. L-Tryptophan as green corrosion inhibitor for low carbon steel in hydrochloric acid solution. J. Mater. Sci. 45, 979-986.

Geethamani, P., Narmatha, M., Dhanalakshm, R., Aejitha, S., Kasthuri, P.K., 2019. Corrosion inhibition and adsorption properties of mild steel in $1 \mathrm{M}$ hydrochloric acid medium by expired ambroxol drug. J. Bio. Tribo Corros. 5 (16) https://doi.org/ 10.1007/s40735-018-0205-5.

Idouhli, R., Oukhrib, A., Koumya, Y., Abouelfida, A., Benyaich, A., Benharref, A., 2017. Inhibitory effect of Atlas cedar essential oil on the corrosion of steel in $1 \mathrm{M} \mathrm{HCl}$. Corrosion Rev. 36 (4) https://doi.org/10.1515/corrrev-2017-0076.

Lahhit, N., Bouyanzer, A., Desjobert, J.-M., Hammouti, B., Salghi, R., Costa, J., Jama, C., Bentiss, F., Majidi, L., 2011. Fennel (Foeniculum Vulgare) Essential oil as green corrosion inhibitor of carbon steel in hydrochloric acid solution. Port. Electrochim. Acta 29 (2), 127-138.

Lai, C., Xie, B., Zou, L., Zheng, X., Ma, X., Zhu, S., 2017. Adsorption and corrosion inhibition of mild steel in hydrochloric acid solution by S-allyl-O, $\mathrm{O}^{\prime}$ dialkyldithiophosphates. Results in Phys 7, 3434-3443. https://doi.org/10.1016/j. rinp.2017.09.012.

Li, Y., Zhao, P., Liang, Q., Hou, B., 2005. Berberine as a natural source inhibitor for mild steel in $1 \mathrm{M} \mathrm{H}_{2} \mathrm{SO}_{4}$. Appl. Surf. Sci. 252, 1245-1253.

Loto, Roland, 2016. Electrochemical analysis of the corrosion inhibition properties of 4 hydroxy-3-methoxybenzaldehyde on low carbon steel in dilute acid media. Cogent Eng. 3 (1), 1242107 https://doi.org/10.1080/23311916.2016.1242107. In this issue.

Loto, Cleophas Akintoye, Joseph, Olufunmilayo, Loto, Roland Tolulope, Popoola, Patricia Abimbola, 2014. Int. J. Electrochem. Sci. 9 (3), 1221-1231. In this issue.

Loto, R.T., Loto, C.A., Joseph, O., Olanrewaju, G., 2016. Adsorption and corrosion inhibition properties of thiocarbanilide on the electrochemical behaviour of high carbon steel in dilute acid solutions. Results in Phys 6, 305. https://doi.org/ 10.1016/j.rinp.2016.05.013, 2016.

Mutahhar, F., Aithan, G., Iski, E.V., Keller, M.W., Shirazi, S., Roberts, K.P., 2017. Chapter 31 - Mechanistic Modeling of Erosion-Corrosion for Carbon Steel, Trends in Oil and Gas Corrosion Research and Technologies, Production and Transmission. Woodhead Publishing Series in Energy, pp. 749-763. https://doi.org/10.1016/B978-0-08101105-8.00031-0.
Novotny, P.M., Banerjee, M.K., 2016. Tool and Die Steels, Reference Module in Materials Science and Materials Engineering. https://doi.org/10.1016/B978-0-12-8035818.02534-0.

Olivares, O., Likhanova, N.V., Gomez, B., Navarrete, J., Llanos-Serrano, M.E., Arce, E., Hallen, J.M., 2006. Electrochemical and XPS studies of decylamides of $\alpha$-amino acids adsorption on carbon steel in acidic environment. Appl. Surf. Sci. 252, 2894-2909, 2006.

ÖZcan, M., 2008. AC impedance measurements of cysteine adsorption at mild steel/ sulphuric acid interface as corrosion inhibitor. J. Solid State Electrochem. 12 1653-1661.

Prabodh, S., Jones, T.H., Lopez, E.M., McFeeters, R.L., Ali, N.A., Mansi, I., Al-kaf, A.G., Setzer, W.N., 2017. Chemotypic characterization and biological activity of rosmarinus officinalis. Foods MDPI 6, 20. https://doi.org/10.3390/foods6030020.

Quartarone, G., Ronchin, L., Vavasori, A., Tortato, C., Bonaldo, L., 2012. Inhibitive action of gramine towards corrosion of mild steel in deaerated 1.0 M hydrochloric acid solutions. Corrosion Sci. 64, 82-89.

Saji, V.S., 2012. Chapter 1 - the Impact of Nanotechnology on Reducing Corrosion Cost, Corrosion Protection and Control Using Nanomaterials. Woodhead Publishing Series in Metals and Surface Engineering, pp. 3-15. https://doi.org/10.1533/ 9780857095800.1 .3

Salghi, R., Ben Hmamou, D., Benali, O., Jodeh, S., Warad, I., Hamed, O., Ebenso, E.E. Oukacha, A., Tahrouch, S., Hammouti, B., 2015. Study of the corrosion inhibition effect of pistachio essential oils in $0.5 \mathrm{M} \mathrm{H}_{2} \mathrm{SO}_{4}$. Int. J. Elect. Sci. 10, 8403-8411.

Schleider, M.W., 2009. Chapter 13 - Business Strategies for Corrosion Control in Fleet Maintenance, Corrosion Control in the Aerospace Industry. Woodhead Publishing Series in Metals and Surface Engineering, pp. 288-298. https://doi.org/10.1533/ 9781845695538.3 .288

Singh, A.K., Thakur, S., Pani, B., Chugh, B., Lgaz, H., Chung, P., Chaubey, I.-M., Pandey, A.K., Singha J, J., 2019. Solvent-free microwave assisted synthesis and corrosion inhibition study of a series of hydrazones derived from thiophene derivatives: experimental, surface and theoretical study. J. Mol. Liq. 283, 788-803.

Soltani, N., Behpour, M., Ghoreishi, S.M., Naeimi, H., 2010. Corrosion inhibition of mild steel in hydrochloric acid solution by some double Schiff bases. Corrosion Sci. 52, 1351-1361.

Umoren, S.A., Eduok, U.M., Solomon, M.M., Udoh, A.P., 2016. Corrosion inhibition by leaves and stem extracts of Sida acuta for mild steel in $1 \mathrm{M} \mathrm{H}_{2} \mathrm{SO}_{4}$ solutions investigated by chemical and spectroscopic techniques. Arab. J. Chem. 9 (1), S209-S224.

Zarras, P., Stenger-Smith, J.D., 2014. Chapter 1 - Corrosion Processes and Strategies for Prevention: an Introduction, Handbook of Smart Coatings for Materials Protection, pp. 3-28. https://doi.org/10.1533/9780857096883.1.3.

Zeldowitsch, J., 1934. Adsorption site energy distribution. Acta Physicochimica URSS 1, 961-973. 